\title{
Effect of pre-germinated brown rice intake on diabetic neuropathy in streptozotocin-induced diabetic rats Seigo Usuki1 ${ }^{1}$ Yukihiko Ito ${ }^{3}$, Keiko Morikawa 3 , Mitsuo Kise ${ }^{3}$, Toshio Ariga ${ }^{1}$, Michael Rivner ${ }^{2}$ and Robert $\mathrm{K} \mathrm{Yu}^{* 1}$
}

\author{
Address: ${ }^{1}$ Institute of Molecular Medicine and Genetics, Medical College of Georgia, Augusta, GA 30912, USA, ${ }^{2}$ Department of Neurology, Medical \\ College of Georgia, Augusta, GA 30912, USA and ${ }^{3}$ FANCL Research Institute, FANCL Corporation, Yokohama, 244-0806, Japan \\ Email: Seigo Usuki - susuki@mcg.edu; Yukihiko Ito - ito@fancl.co.jp; Keiko Morikawa - morikawa@fancl.co.jp; \\ Mitsuo Kise - mikise@fancl.co.jp; Toshio Ariga - tariga@mcg.edu; Michael Rivner - mrivner@mcg.edu; Robert K Yu* - ryu@mcg.edu \\ * Corresponding author
}

Published: 23 November 2007

Nutrition \& Metabolism 2007, 4:25 doi:10.1 186/1743-7075-4-25
Received: 27 August 2007

Accepted: 23 November 2007

This article is available from: http://www.nutritionandmetabolism.com/content/4/I/25

(c) 2007 Usuki et al; licensee BioMed Central Ltd.

This is an Open Access article distributed under the terms of the Creative Commons Attribution License (http://creativecommons.org/licenses/by/2.0), which permits unrestricted use, distribution, and reproduction in any medium, provided the original work is properly cited.

\begin{abstract}
Background: To study the effects of a pre-germinated brown rice diet (PR) on diabetic neuropathy in streptozotocin (STZ)-induced diabetic rats.

Methods: The effects of a PR diet on diabetic neuropathy in STZ-induced diabetic rats were evaluated and compared with those fed brown rice (BR) or white rice (WR) diets with respect to the following parameters: blood-glucose level, motor-nerve conduction velocity (NCV), sciaticnerve $\mathrm{Na}^{+} / \mathrm{K}^{+}$-ATPase activity, and serum homocysteine-thiolactonase (HTase) activity.

Results: Compared with diabetic rats fed BR or WR diets, those fed a PR diet demonstrated significantly lower blood-glucose levels $(p<0.001)$, improved NCV $(1.2-$ and I.3-fold higher, respectively), and increased $\mathrm{Na}^{+} / \mathrm{K}^{+}$-ATPase activity (I.6- and I.7-fold higher, respectively). The PR diet was also able to normalize decreased serum homocysteine levels normally seen in diabetic rats. The increased $\mathrm{Na}^{+} / \mathrm{K}^{+}$-ATPase activity observed in rats fed PR diets was associated with elevations in HTase activity $(r=0.913, p<0.00 \mathrm{I})$. The in vitro effect of the total lipid extract from PR bran (TLP) on the $\mathrm{Na}^{+} / \mathrm{K}^{+}$-ATPase and HTase activity was also examined. Incubation of homocysteine thiolactone $(\mathrm{HT})$ with low-density lipoprotein (LDL) in vitro resulted in generation of $\mathrm{HT}$-modified $\mathrm{LDL}$, which possessed high potency to inhibit $\mathrm{Na}^{+} / \mathrm{K}^{+}-\mathrm{ATPase}$ activity in the sciatic nerve membrane. The inhibitory effect of $\mathrm{HT}$-modified $\mathrm{LDL}$ on $\mathrm{Na}^{+} / \mathrm{K}^{+}$-ATPase activity disappeared when TLP was added to the incubation mixture. Furthermore, TLP directly activated the HTase associated with high-density lipoprotein (HDL).
\end{abstract}

Conclusion: PR treatment shows efficacy for protecting diabetic deterioration and for improving physiological parameters of diabetic neuropathy in rats, as compared with a BR or WR diet. This effect may be induced by a mechanism whereby PR intake mitigates diabetic neuropathy by one or more factors in the total lipid fraction. The active lipid fraction is able to protect the $\mathrm{Na}^{+} / \mathrm{K}^{+}$ATPase of the sciatic-nerve membrane from the toxicity of HT-modified LDL and to directly activate the HTase of HDL. 


\section{Background}

Pre-germinated brown rice (PR), prepared by soaking brown rice (BR) in $37^{\circ} \mathrm{C}$ water for $24 \mathrm{~h}$ to initiate germination of sprouts not exceeding $0.5-\mathrm{mm}$ in length [1], is a commercial dietary supplement in Japan. The efficacy of PR-enriched diets in reducing blood glucose levels in streptozotocin (STZ)-induced diabetic rats has been reported [2]. STZ, which induces type 1 diabetes mellitus when delivered to rats, is a useful etiological model for studying complications caused by diabetic hyperglycemia.

In clinical studies, we previously showed that both nondiabetic patients and hyperglycemic patients with uncontrolled diabetes who ate diets supplemented with PR had lower postprandial blood-glucose levels than those who ate white rice (WR)-supplemented diets $[3,4]$. It has been suggested that the reduction in blood-glucose levels and the incidence of diabetic vascular complications in diabetic patients fed a PR-rich diet may result from the substantially higher dietary fiber content of germinating rice bran [5]. However, the $\gamma$-aminobutyric acid (GABA) produced during germination of BR or the vitamins, minerals and/or unknown bioactive lipids in the bran and germ layer of PR may also be associated with PR's effect on blood-glucose levels [6,7]. Reduced type-1 plasminogenactivator inhibitor and lipid-peroxide levels have been reported in diabetic rats [2], suggesting that PR intake may ameliorate diabetic vascular complications such as retinopathy and nephropathy.

Another major complication of diabetes is peripheral neuropathy, which occurs in greater than $50 \%$ of diabetics. Early nervous system dysfunctions in diabetics include reduced nerve conduction velocity (NCV), which frequently is followed by axonal degeneration and paranodal demyelination [8]. It is of interest, therefore, to compare PR and BR diets during the development of diabetic neuropathy. We undertook a study to investigate the difference in the effectiveness of PR and BR diets in rats with STZ-induced diabetic neuropathy.

The neuropathy seen in the well-characterized STZinduced diabetic rat model shares many of the same pathological, functional, and biochemical alterations seen in human diabetic $[9,10]$. In particular, gradual decreases in $\mathrm{Na}^{+} / \mathrm{K}^{+}$-ATPase activity and NCV are observed in the sciatic nerves of STZ-treated rats. Recent findings suggest that depressed activity of $\mathrm{Na}^{+} / \mathrm{K}^{+}$-ATPase, a plasma membranebound enzyme, is a hallmark of diabetic neuropathy [11]. PR-enriched diets have shown promise in ameliorating many vascular diabetic sequelae in human patients according to Japanese folk medicine; however, there is little systematic scientific study regarding its nutritional functions. We were interested in investigating the comparative effects of PR- and BR-enriched diets on the develop- ment of diabetic neuropathy in STZ-induced diabetes in rats. We decided to investigate the effect of PR- and BRenriched diets specifically on NCV and sciatic nerve $\mathrm{Na}^{+}$/ $\mathrm{K}^{+}$-ATPase activities in STZ-induced diabetes in rats.

Diabetic neuropathy is also thought to develop as a result of damage caused by oxidative stress and other vascular risk factors [12,13]. Homocysteine-thiolactone (HT) is formed from an excess amount of serum homocysteine (Hcy) and causes protein homocysteinylation and subsequent protein damage. In particular, homocysteinylated low-density serum lipoproteins (LDLs) are more susceptible to lipid peroxidation. On the other hand, high-density lipoproteins (HDLs) are resistant to homocysteinylation because of an associated homocysteine-thiolactonase (HTase) that hydrolyzes HT; this hydrolysis prevents subsequent HDL lipid peroxidation. HT is reported to produce oxidative stress in rat hippocampal neurons by inhibiting $\mathrm{Na}^{+} / \mathrm{K}^{+}$-ATPase activity $[14,15]$. Further, Vignini et al. [16] reported that HT-modified LDL attenuates $\mathrm{Na}^{+} / \mathrm{K}^{+}$-ATPase activity in cultured human aortic endothelial cells.

HT is thought to be an endogenous substrate for three isozymes of the serum esterase paraoxonase (PON): PON1, PON2, and PON3 [17]. PON1 has been shown to be involved in the detoxification of various organophosphatases, such as nerve gases, dietary neurotoxins, or toxic lipids produced during oxidative stress [18]. Serum PON1 activity is decreased in type 2 diabetic patients with atherosclerosis [19] and in STZ-induced type 1 diabetic rats [20]. Decreased PON1 activity is also observed in patients with type 1 and type 2 diabetic peripheral neuropathy, suggesting that diabetic neuropathy may also arise, in part, due to the increased susceptibility of the nervous system to neurotoxic damage resulting from the lack of protection in diabetics normally afforded by PON1 in non-diabetics [21]. The role of PON1 activity in HDL in diabetes has become an important concern [22,23]. For this reason, HTase activity can be another important biomarker for evaluating diabetic neuropathy, especially when estimation of this enzyme activity requires HT to be a natural substrate. To assess the effects of a PR-enriched diet on the development of diabetic neuropathy, we also evaluated the effect of PR- and BR-enriched diets on serum PON1 activities in STZ-induced diabetic rats.

In addition, circumstantial evidence suggests that other bioactive components are present in PR bran that are more potent than GABA in alleviating diabetic neuropathy. To test this possibility, we isolated the total lipid extracts (TLP) from PR and BR and compared the effects of these lipid fractions on HTase activity. 


\section{Methods}

STZ-induced diabetic rats and experimental diets

Male Wistar rats, weighing 120-140 g, received intra-peritoneal injections of STZ $(65 \mathrm{mg} / \mathrm{kg}$ in $100 \mathrm{mM}$ sodium citrate buffer, $\mathrm{pH} 4.5$ ). The use of these animas had been approved by Medical College of Georgia's Institutional Animal Care and Use Committee. Beginning 1 week after STZ injection, blood samples were obtained at each time point from the same rats following a 15-hour starvation period by pricking the tip of the rat tail and bleeding a drop (about $0.06 \mathrm{ml}$ ) of blood. The whole blood was obtained from each rat by heart puncture at the endpoint of the experiment. The blood-glucose levels were measured using a strip-operated blood glucose meter (AccuChek Advantage Blood Glucose Meter, Roche Diagnostics, Indianapolis, IN). Two animals were housed per cage in a controlled environment. All animals were allowed free access to water and food, except during the starvation periods just prior to blood glucose assessments.

All rice and control diets were manufactured as powdered feed by Harlan Teklad (Madison, WI). The control diet (AIN93G) was composed of cornstarch [39.7\% (w/w)], $\alpha$ cornstarch $[13.2 \%(\mathrm{w} / \mathrm{w})]$, casein $[20.0 \%(\mathrm{w} / \mathrm{w})]$, Lcysteine $[0.3 \%(\mathrm{w} / \mathrm{w})]$, sucrose $[10 \%(\mathrm{w} / \mathrm{w})]$, soybean oil $[7.0 \%(\mathrm{w} / \mathrm{w})]$, cellulose powder $[5.0 \%(\mathrm{w} / \mathrm{w})]$, mineral $\operatorname{mix}[3.5 \%(\mathrm{w} / \mathrm{w})]$, vitamin $\operatorname{mix}[1.0 \%(\mathrm{w} / \mathrm{w})]$, choline bicitrates $[0.25 \%(\mathrm{w} / \mathrm{w})]$, and_butylhydroquinone $[0.0014 \%(w / w)]$. Pre-germinated brown (PR), brown (BR), or white (WR) rice diets were produced by replacing cornstarch and $\alpha$-cornstarch with pre-germinated brown, brown, or white rice, respectively (Table 1 ).

\section{Animal experiment design}

Male Wistar rats $(n=40)$ received intra-peritoneal injections of STZ and were maintained on AIN93G for 2 weeks. Only those animals whose blood glucose levels were > $400 \mathrm{mg} / \mathrm{dl}$ were considered diabetic. The diabetic rats $(\mathrm{n}=$ 31) were divided into four experimental groups: the DWR $(n=9), \operatorname{DBR}(n=9)$, and DPR $(n=9)$ groups received WR, BR-, and PR-enriched diets, respectively, and DC group $(\mathrm{n}=4)$ were fed AIN93G. Non-diabetic rats $(\mathrm{n}=22)$ were also divided into four feeding groups: the WR $(n=6)$, BR $(n=6)$, and PR $(n=6)$ groups received WR-, BR-, and PR- enriched diets, respectively, while the $\mathrm{C}$ control group ( $\mathrm{n}$ $=4$ ) received AIN93G.

Because rats became moribund with severe diabetic deterioration initiating 3 weeks after STZ injection, the experimental endpoint was designated 3 weeks after initiation of the rice-enriched diet regimens (i.e., 5 weeks after STZinjection). Food consumption was measured by weighing the feeding containers daily. Three weeks after initiation of the rice-enriched diets, tail-nerve conduction electrophysiological studies were performed, and then the rats were sacrificed. Whole serum samples were obtained for biochemical analyses as described below. The sciatic nerves were removed; the right sciatic nerve was utilized for morphometric studies while the left sciatic nerve was assayed for $\mathrm{Na}^{+} / \mathrm{K}^{+}$-ATPase activities.

\section{Nerve-conduction velocity measurements}

Nerve-conduction velocities (NCVs, m/sec) were assessed in the rat tail nerve using a Nicolet VikingQuest EMG machine (Neurocaregroup, Madison, WI) according to the modified procedure of Anderson et al. [24]. In brief, the nerves were stimulated using external digital ring electrodes with twisted wires (Medtronic Functional Diagnostics, Skovlunde, Denmark) instead of needle electrodes [25]. The electrodes were placed in segments proximal (5 $\mathrm{cm})$ and distal $(2 \mathrm{~cm})$ from the recording position $(7 \mathrm{~cm}$ far from the joint of rat tail). Blood collection was from the tip of the tail that was distant and non-interactive with NCV measurement. NCV was evaluated from four different waves generated from electrical stimulations; each wave showed a reproducible pattern and the same amplitude level as the stimulator-voltage was increased. During each measurement, a constant surface temperature of the rat tail was maintained $\left(34-35^{\circ} \mathrm{C}\right)$. NCV values represent an average value from 4 nerve conduction wave measurements per animal.

\section{Morphometric analysis}

The right sciatic nerves were carefully dissected from their origin ( $5 \mathrm{~mm}$ distal to the gluteus maximus) through the distal branch point at the peroneal and tibial nerves in order to avoid stretching. These nerve sections were placed overnight in a fixative solution containing paraformaldehyde. After washing 3 times in cacodylate buffer ( $\mathrm{pH} 7.2$ ),

Table I: Com position of experim ental diets ( $\mathrm{g} / 100 \mathrm{~g})$

\begin{tabular}{ccccc}
\hline Ingredient & AIN93G & WR & BR & PGR \\
\hline Protein & 17.7 & 21.5 & 21.6 & 21.8 \\
Fat & 7.2 & 7.0 & 8.3 & 8.1 \\
Available carbohydrate & 55.1 & 53.4 & 50.0 & 50.4 \\
Dietary fiber & 5.0 & 5.6 & 374.1 & 6.7 \\
Total energy(kcal/l00 g) & 366.0 & 373.8 & 375.1 \\
\hline
\end{tabular}

Values are calculated from ingredient analysis or $\mathrm{m}$ anufacturer data 
the nerves were cross-sectioned into two pieces and embedded in epoxy resin (Poly/Bed 812, Polysciences Inc., Warrington, PA). Fascicle cross sections were stained with $1 \%$ toluidine blue and observed under an Axiophot photomicroscope equipped with an Axiocam (Carl Zeiss, Jena, Germany). Images were stored and analyzed using AxioVision. The total number of myelinated fibers in each fascicle was assessed by visual counting. In myelinated fibers, both the axonal and total fiber diameters were measured, based on the average of the major and minor diameters. Diameters of the myelinated fibers and axons, as well as the $\mathrm{G}$ ratio (axonal diameter/total fiber diameter, a measure of the degree of myelination), were obtained, and histograms of their distributions and the $G$ ratios were constructed as percentages of size frequency.

\section{Total lipid preparation}

The total lipid fractions from PR and BR bran (TLp and TLb, respectively) were prepared by extracting $5 \mathrm{~g}$ of bran twice with $30 \mathrm{ml}$ and $20 \mathrm{ml}$ of chloroform-methanol (1:1 $(\mathrm{v} / \mathrm{v})$ and $2: 1(\mathrm{v} / \mathrm{v})$, respectively) using the procedure of Folch et al. [26]. Lipid fractions from these two extractions were combined, evaporated, and used in in vitro enzyme assays.

\section{Lipoprotein separation}

Lipoprotein fractions were prepared from rat serum using previously published procedures [27]. Briefly, freshly collected serum obtained from normal male Wistar rats $(\mathrm{n}=$ 4) was pooled and adjusted to a density of $1.3 \mathrm{~g} / \mathrm{ml}$ with solid potassium bromide. A discontinuous density gradient was formed in a centrifuge tube by layering normal saline $(3.5 \mathrm{ml}, 1.006 \mathrm{~g} / \mathrm{ml})$ over the adjusted serum $(1.5$ $\mathrm{ml}, 1.3 \mathrm{~g} / \mathrm{ml}$ ). Lipoproteins were separated by ultracentrifugation $\left(370,000 \times \mathrm{g}, 45 \mathrm{~min}, 4^{\circ} \mathrm{C}\right)$ in a TV865 rotor. Three major lipoprotein fractions (VLDL, LDL, and HDL) were collected and dialyzed overnight against PBS at $4{ }^{\circ} \mathrm{C}$.

\section{Sciatic nerve membrane preparation for the $\mathrm{Na}^{+} / \mathrm{K}^{+}-$ ATPase assay}

Crude sciatic nerve membranes were prepared from each rat of the diet experiment using a previously published procedure [28]. Briefly, the left sciatic nerve from rats fed WR-, BR-, or PR-enriched diets, or AIN93G, or from untreated male Wistar rats were homogenized in Polytron homogenizer in a cold iso-osmotic solution containing $250 \mathrm{mM}$ sucrose, $10 \mathrm{mM}$ HEPES-Tris buffer ( $\mathrm{pH}$ 7.6), EDTA $2 \mathrm{mM}$, and PSMF $1 \mathrm{mM}$. The homogenates were centrifuged for $10 \mathrm{~min}$ at $1,500 \times \mathrm{g}$ at $4{ }^{\circ} \mathrm{C}$; the supernatants were collected and then centrifuged at 191,000 $\times \mathrm{g}$ for $45 \mathrm{~min}$ at $4^{\circ} \mathrm{C}$. After decanting the supernatant, the pellets were resuspended in $100 \mu \mathrm{l}$ of $250 \mathrm{mM}$ sucrose in $10 \mathrm{mM}$ HEPES-Tris buffer ( $\mathrm{pH}$ 7.6).

\section{$\mathrm{Na}^{+} / \mathrm{K}^{+}$-ATPase assay}

$\mathrm{Na}^{+} / \mathrm{K}^{+}$-ATPase activities were assayed as previously described [28]. Briefly, a $0.2 \mathrm{ml}$ assay medium containing $10 \mathrm{mM} \mathrm{MgCl} 2,20 \mathrm{mM}$ HEPES-Tris (pH 7.0), $120 \mathrm{mM}$ $\mathrm{NaCl}, 30 \mathrm{mM} \mathrm{KCl}, 0.5 \mathrm{mg} / \mathrm{ml}$ of crude membrane preparations, and $25 \mathrm{mM}\left[\gamma_{-32}\right.$ P]ATP $(100,000 \mathrm{cpm})$ were incubated at $37^{\circ} \mathrm{C}$ for $15 \mathrm{~min}$, followed by the addition of 0.1 $\mathrm{ml}$ of activated carbon $(0.1 \mathrm{mg} / \mathrm{ml})$. Parallel assays were also performed in which $1 \mathrm{mM}$ ouabain was added to the assay medium. Following the addition of activated carbon, the samples were centrifuged at $1,500 \times \mathrm{g}$ for $15 \mathrm{~min}$ at $4{ }^{\circ} \mathrm{C}$, the supernatants were collected, and the cpm of the inorganic ${ }^{32} \mathrm{P}$ radioactivity in the fractions was measured using a Beckman scintillation counter. Ouabain-sensitive $\mathrm{Na}^{+} / \mathrm{K}^{+}$ATPase activity was calculated by subtracting the ouabain-sensitive activity from the $\mathrm{Na}^{+} / \mathrm{K}^{+}$-enhanced activity.

\section{Paraoxonase I (PONI) activity assays}

PON1 activity was measured in 96-well ELISA plates; each well contained $20 \mu \mathrm{l}$ of rat serum (diluted 1:4 in Tris- $\mathrm{HCl}$ buffer) and $200 \mu \mathrm{l}$ of substrate solution containing 5.5 $\mathrm{mM}$ paraoxoethyl and $2 \mathrm{mM} \mathrm{CaCl}_{2}$ in $100 \mathrm{mM}$ Tris- $\mathrm{HCl}$ buffer ( $\mathrm{pH} 8.0$ ). Generation of $p$-nitrophenol was monitored as a function of time at $25^{\circ} \mathrm{C}$ by recording the absorbance at $412 \mathrm{~nm}$ using a spectrophotometer. Enzyme activities were calculated using the molar absorption coefficient of $p$-nitrophenol $\left(\varepsilon_{412}{ }^{\mathrm{M}}, 169,000 \mathrm{M}^{-1} \mathrm{~cm}^{-}\right.$ $1)$.

\section{Homocysteine-thiolactonase (HTase) activity assays}

HTase activities in rat serum or in HDL fractions from normal male Wistar rats were measured with a commercial assay kit (Alfresa Auto HTLase; Alfresa Pharma Corp., Osaka, Japan) [23] that utilizes $\gamma$-thiobutyrolactone as the substrate. HTase hydrolyzes the lactone ring, generating free thiol, which reacts with 5, 5'-dithio-bis (2-nitrobenzoic acid). Generation of 5-thio-2-nitrobenzoic acid was monitored as a function of time by recording the absorbance at $450 \mathrm{~nm}$ using a spectrophotometer.

\section{Incubation of homocysteine-thiolactone (HT) with low- density lipoprotein (LDL)}

In vitro homocysteinylation of LDL was done according to the procedure of Vignini et al. [16]. Briefly, an aliquot of LDL (100 $\mu \mathrm{g})$ was resuspended in $10 \mathrm{mM}$ PBS (pH 8.2) and incubated with homocysteine-thiolactone (100 $\mu \mathrm{mol} / \mathrm{L}$, Sigma, St. Louis, MO) and the indicated amount $(0.1$ to $1.0 \mu \mathrm{g})$ of a total lipid fraction (TLb or TLp) with gentle stirring at $37^{\circ} \mathrm{C}$ for $2 \mathrm{~h}$. After incubation, the mixture was passed through a Bio-gel P-2 column equilibrated with $10 \mathrm{mM}$ PBS ( $\mathrm{pH} 8.2$ ) to remove any unreacted HT. 


\section{Serum creatinine determination}

The creatinine concentrations in rat serum samples were assayed by Jaffe's alkaline-picrate method as described by Adeoye et al. [29]. Proteins were precipitated from $1 \mathrm{ml}$ of serum by the addition of $1 \mathrm{ml} 10 \%$ sodium tungstate in 1 $\mathrm{ml}$ of $0.67 \mathrm{M}$ sulfuric acid, and the supernatants were collected; $1.5 \mathrm{ml}$ of the supernatants were mixed with $0.5 \mathrm{ml}$ of $2.5 \mathrm{M} \mathrm{NaOH}$ and $0.5 \mathrm{ml}$ of $0.04 \mathrm{M}$ picric acid, and then incubated for $5 \mathrm{~min}$ at $25^{\circ} \mathrm{C}$. The absorbance at $520 \mathrm{~nm}$ was measured in each sample against a blank that consisted of distilled water with the reagent as described above using a spectrophotometer.

\section{Statistical analysis}

Statistical analyses were performed for animal data using the GraphPad Prism 2.01 software package (GraphPad, San Diego, CA). Differences among diet groups with nondiabetic treatment or with diabetic treatment were analyzed using the one-way ANOVA (Table 2) test. Normalization of data distribution was given by Prism 2.01 before the comparison test. If the data were found to be parametric, they were analyzed by Tukey's multiple comparison test, followed by determination of differences vs. the control group after obtaining a significant ANOVA by the Dunnet's test. If the data were non-parametric, they were analyzed by the Kruskal-Wallis test of one way analysis of variance on rank, followed by Dunn's multiple comparison test. Differences among the diet treatment groups were considered significant if $\mathrm{p}<0.01$. For comparisons of size-frequency distributions, the difference of skewness was evaluated by the chi-square test for trend in the Prism 2.01 to evaluate the statistical difference of skewness. A value of $p<0.01$ was considered a statistically significant difference.
In correlation analyses, Pearson correlation coefficients were calculated to identify potential associations of the HTase, PON1, NCV, and $\mathrm{Na}^{+} / \mathrm{K}^{+}$-ATPase activities. A value of $p<0.05$ was considered a statistically significant difference. Data were presented as mean \pm standard error of the mean (SEM).

\section{Results \\ Body weight and blood-glucose level}

The total mass of food consumed during the 3-week experimental diet period for each non-diabetic rat group was as follows: WR, $590 \pm 31 \mathrm{~g}$; BR, $611 \pm 42 \mathrm{~g}$; and PR, $631 \pm 64 \mathrm{~g}$. The total mass of food consumed during the same period for each diabetic rat group was as follows: DWR, $641 \pm 58 \mathrm{~g} ; \mathrm{DBR}, 658 \pm 30 \mathrm{~g}$; and DPR $631 \pm 53 \mathrm{~g}$. The consumption rates were not significantly different among the normal and diabetic rats fed WR-, BR-, and PRenriched diets (assessed by the Kruskal-Wallis test followed by Dunn's test).

The body-weight gain in the WR, BR, and PR groups was smooth, and no differences were observed among the three groups. Modest body-weight gain due to diabetes was observed in the DWR, DBR, and DPR groups, and considered to be a well-established phenomenon in insulin-deficiency caused by STZ treatment in the rat [30]. There were also no statistically significant differences in body-weight gain between rats fed a rice-enriched diet and those fed the control AIN93G diet. The DPR group, however, had statistically significant body-weight gain as compared with the DC group ( $p<0.01$, Dunnett's test) but not with the DBR group, as shown in Table 2.

All the blood-glucose levels of the non-diabetic AIN93Gand rice-diet groups $(\mathrm{C}, \mathrm{PR}, \mathrm{BR}$ and $\mathrm{WR})$ were within the normal range during the experimental period (Table 2). In

Table 2: Final body weights, blood glucosse concentrations, and peripheral nerve or serum parameters in non-diabetic and diabetic rats ( 3 weeks) sacrificed at the end of the diet-feeding experiment

\begin{tabular}{|c|c|c|c|c|c|c|c|c|}
\hline \multirow{2}{*}{$\begin{array}{c}\text { Treatment } \\
\text { Diet }\end{array}$} & \multicolumn{4}{|c|}{ Non-diabetic } & \multicolumn{4}{|c|}{ Diabetic } \\
\hline & $\mathrm{C}$ & WR & BR & PR & $\mathrm{C}$ & WR & BR & PR \\
\hline Group & C & WR & $B R$ & PR & $\mathrm{DC}$ & DWR & DBR & DPR \\
\hline Number of animals & 4 & 6 & 6 & 6 & 4 & 9 & 9 & 9 \\
\hline Weight (g) & $373.8 \pm 7.8$ & $374.7 \pm 3.8$ & $370.3 \pm 9.1$ & $384.8 \pm 13.5$ & $174.0 \pm 8.6$ & $174.2 \pm 4.8$ & $183.9 \pm 2.7 b$ & $209.0 \pm 3.3 \mathrm{a} *$ \\
\hline Glucose (mg/dl) & $127.0 \pm 1.8$ & $135.5 \pm 2.7$ & $129.0 \pm 3.3$ & $126.7 \pm 4.0$ & $438.0 \pm 11.0$ & $431.0 \pm 9.3$ & $405.2 \pm 9.1$ & $351.9 \pm 6.3 \mathrm{a} *$ \\
\hline $\mathrm{NCV}(\mathrm{m} / \mathrm{s})$ & $50.4 \pm 0.8$ & $49.9 \pm 1.3$ & $50.2 \pm 0.8$ & $50.4 \pm 0.9$ & $34.0 \pm 1.4$ & $34.4 \pm 0.8$ & $37.9 \pm 1.1$ & $44.5 \pm 1.3 \mathrm{a} *$ \\
\hline $\mathrm{Na}^{+} / \mathrm{K}^{+}-$ATPase $(\mu \mathrm{mol} / \mathrm{g} / \mathrm{h})$ & $6102.5 \pm 218.9$ & $4855 \pm 463.4$ & $6998 \pm 515.6$ & $6302 \pm 371.5$ & $2238 \pm 102$ & $2229.3 \pm 153.0$ & $2437.2 \pm 189.9$ & $3867.8 \pm 177.6 a *$ \\
\hline Homocysteine $(\mu \mathrm{M})$ & $6.3 \pm 0.3$ & $5.9 \pm 0.1$ & $6.1 \pm 0.2$ & $6.3 \pm 0.2$ & $3.3 \pm 0.2$ & $3.1 \pm 0.2$ & $4.2 \pm 0.1 b *$ & $5.3 \pm 0.1 \mathrm{a} *$ \\
\hline $\mathrm{PON} I$ (nmol/ml/min) & $224.0 \pm 11.1$ & $217.9 \pm 4.4$ & $216.0 \pm 4.6$ & $239.5 \pm 6.5$ & $118.4 \pm 7.4$ & $117.4 \pm 5.9$ & $158.3 \pm 8.4^{a}$ & $187.7 \pm 13.6$ a* \\
\hline HTase (nmol/mg/min) & $9.8 \pm 0.4$ & $10.0 \pm 0.2$ & $10.2 \pm 0.3$ & $10.3 \pm 0.3$ & $2.0 \pm 0.3 c$ & $1.8 \pm 0.2 \mathrm{c}$ & $4.3 \pm 0.2$ b** & $8.9 \pm 0.2 \mathrm{a} * *$ \\
\hline Creatinine $(\mu \mathrm{mol} / \mathrm{l})$ & $67.3 \pm 1.7$ & $60.3 \pm 1.6$ & $59.7 \pm 1.3 \mathrm{a} *$ & $59.5 \pm 1.0 \mathrm{a} *$ & $89.3 \pm 1.7$ & $88.3 \pm 1.1$ a & $82.5 \pm 1.3 \mathrm{~b} *$ & $72.8 \pm 1.1 \mathrm{c}^{\mathrm{c} *}$ \\
\hline
\end{tabular}

One-way ANOVA was performed for 4 groups of non-diabetic treatment or diabetic treatment, followed by Tukey's multiple comparison test (if parametric). Difference vs. control (C group or DC group) was analyzed by Dunnet's multiple comparison test (*P $\left.<0.0 \mathrm{I},{ }^{* * P}, 0.00 \mathrm{I}\right)$. KruskalWallis test was performed for the groups (if non-parametric) followed by Dunn's multiple comparison test. Values are means \pm SEM. a,b,c Values with different superscript letters are significantly different among the same column at $\mathrm{P}<0.0 \mathrm{I}$. 
contrast, the blood-glucose levels of the diabetic rats fed the AIN93G, WR-, BR-, or PR-enriched diets (i.e., DC, DWR, DBR, and DPR groups, respectively) were elevated. During the initial week of the rice-enriched diet regimen, all diabetic groups demonstrated high blood-glucose levels (Table 2); after 3 weeks of the rice-enriched diets, however, the blood glucose levels of the DPR group were significantly lower than those of the DWR and DBR groups ( $p<0.001$, Tukey's test), as shown in Table 2 .

\section{Amelioration of peripheral nerve dysfunction}

A positive correlation was established between values for $\mathrm{NCV}$ and $\mathrm{Na}^{+} / \mathrm{K}^{+}$-ATPase activities in non-diabetic and STZ-diabetic rats (Fig. 1). The data also include rats fed by a regular diet (AIN93G). This result demonstrates that decreased sciatic-nerve $\mathrm{Na}^{+} / \mathrm{K}^{+}$-ATPase activities are likely to result in electrophysiological and neurophysiological abnormalities. Comparison of the effects of the diet intakes on NCV and $\mathrm{Na}^{+} / \mathrm{K}^{+}$-ATPase activity is shown in Table 2, expressed as mean \pm SEM. Diabetic rats fed the control diet (AIN93G) showed significantly decreased NCVs when compared with those in the non-diabetic rats. NCVs in the DPR group, on the other hand, were significantly faster than those observed in the DC, DWR or DBR group ( $p<0.001$, Tukey's test). $\mathrm{Na}^{+} / \mathrm{K}^{+}$-ATPase activities in the DPR group were also significantly higher than those seen in the DBR, DWR, and DC groups ( $p<0.001$, Tukey's test), as shown in Table 2.

\section{Morphometric analysis of sciatic nerve}

Size-frequency distribution histograms for myelinated fiber diameter, myelinated axon diameter, and the $\mathrm{G}$ ratio

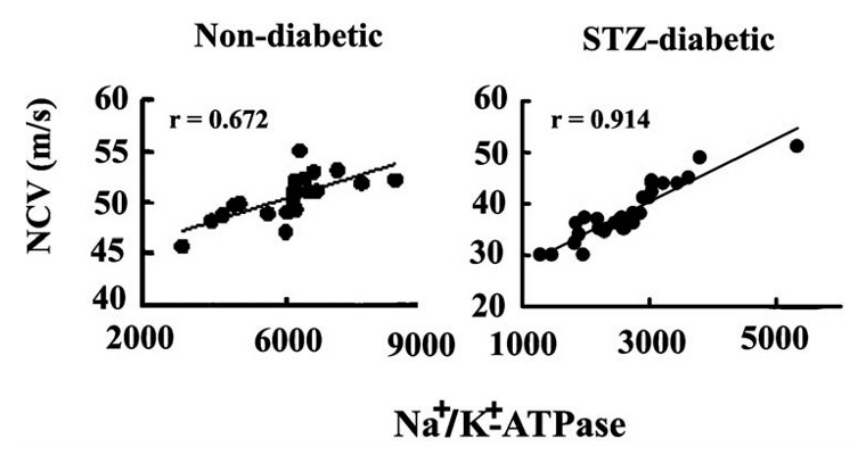

\section{Figure I}

Correlation of NCV and sciatic-nerve membrane $\mathrm{Na}^{+} / \mathrm{K}^{+}$ATPase activities in non-diabetic rats $(n=22)$ and STZinduced diabetic rats $(n=3 I)$. Non-diabetic rats consisted of C-group $(n=4)$, WR-group $(n=6)$, BR-group $(n=6)$, and PR-group $(n=6)$. STZ-diabetic rats consisted of DC-group $(n=4)$, DWR-group $(n=9)$, DBR-group $(n=9)$, and DPRgroup $(n=9)$. Regression lines are shown for analyses that include all data points $(n=22$ and $n=31$ ). Pearson's correlation coefficients $(r)$ were used to evaluate simple linear relationship between variables. in rat sciatic nerves were evaluated by the chi-square test for trend in the Prism 2.01, and compared among three groups: a non-diabetic group fed the AIN93G diet (C group); a diabetic group fed the AIN93G diet (DC group); and a diabetic group fed the PR diet (DPR group). There was no statistically significant difference between myelinated fiber distributions; one difference between axonal distributions for the $\mathrm{C}$ and DC groups, however, indicated that the STZ rat model of diabetes primarily affected axons. Since the $\mathrm{G}$ ratio is a reflection of the diameters of axons and myelinated fibers, these observations indicate that PR intake could prevent or correct myelinated axonal injury in the STZ model of diabetic neuropathy (data not shown).

\section{PONI and HTase}

Serum activities for creatinine or PON1 and HTase in the diabetic and non-diabetic animals are shown in Table 2 as means \pm SEM. Given that the non-diabetic groups had similar weight gains and diet consumptions, we cannot attribute the changes in serum homocysteine concentrations to differences in vitamin or amino-acid intake in the rice diets. The decreased homocysteine levels in the diabetic rats indicate that increased creatinine levels may reflect diabetic complications such as nephropathy. The serum homocysteine level and PON1 activity in the DPR group sera were affected by STZ-induced diabetes, which was not the case in the DC, DWR and DBR groups $(p<$ 0.001, Tukey's test) (Table 2).

To determine whether the PR-diet promoted amelioration of the nervous function by a specific active component of PR due to an HT-related mechanism, a correlation analysis was performed between activities of $\mathrm{Na}^{+} / \mathrm{K}^{+}$-ATPase and HTase (or PON1) for each group of Table 2. A positive correlation was established between activities of serum HTase and PON1 in all the diet-treated and the control groups ( $\mathrm{r}=0.819$ to 0.992$)$. On the other hand, a positive correlation between $\mathrm{Na}^{+} / \mathrm{K}^{+}$-ATPase and HTase activities was established only in the DPR $(r=0.913, \mathrm{p}<0.001)$ and PR groups $(r=0.878, p<0.05)$. Other diet-treated groups showed no correlation between the two enzyme activities. Although the DBR group showed an improvement in diabetic neuropathy, there was no correlation between the two enzyme activities in DBR group $(\mathrm{r}=-0.217$, non-significant) and BR group ( $\mathrm{r}=-0.142$, non-significant $)$.

\section{Homcysteine-thiolactonation of LDL}

HT causes LDL deterioration, resulting in the development of diabetic complications as a vascular risk factor by HT-modified LDL. HTase is present in serum HDL and has an important role in the antioxidation of LDL. We hypothesized that the efficacy of a PR diet on diabetic neuropathy might be dependent on an HT-related mechanism. To test this possibility, an additional effect of rice 
bran lipid extracted fractions (TLp or TLb) on $\mathrm{Na}^{+} / \mathrm{K}^{+}$ ATPase activity was tested with HT-treated LDL. Changes in the $\mathrm{Na}^{+} / \mathrm{K}^{+}$-ATPase activity of normal rat sciatic nerve was studied by incubation of HT-treated LDL with HT and TLp or TLb (Fig. 2A). A significant decrease in $\mathrm{Na}^{+} / \mathrm{K}^{+}$ ATPase activity occurred in an in vitro system incubated with HT-modified LDL as compared with intact LDL. Incubation with TLp $(0.1 \mu \mathrm{g}$ to $10 \mu \mathrm{g})$ attenuated the inhibitory activity of HT-modified LDL on $\mathrm{Na}^{+} / \mathrm{K}^{+}$-ATPase activity (columns 7 to 9, Fig. 2A), whereas TLb had no effect on the inhibition of $\mathrm{Na}^{+} / \mathrm{K}^{+}$-ATPase activity by HTmodified LDL (columns 4 to 6, Fig. 2A). Neither TLp nor TLb alone produced any modification of $\mathrm{Na}^{+} / \mathrm{K}^{+}$-ATPase activity (data not shown). The effect of TLp suggests the presence of an inhibitory factor causing normalization of $\mathrm{Na}^{+} / \mathrm{K}^{+}$-ATPase activity that has been blocked by HT-modified LDL.

\section{HTase activity of HDL}

In the previous experiment, we showed that $\mathrm{Na}^{+} / \mathrm{K}^{+-}$ ATPase activity was controlled by HT-modified LDL. The efficacy of PBR on diabetic neuropathy may be related to the HTase activity of HDL on an HT-related mechanism. To verify this possibility, the effect of rice bran lipid extracted fractions (TLp or TLb) on HTase activity was tested. HDL prepared from normal male Wistar rat serum was used as an enzyme source of HTase as described in the Methods section. HTase activity in the presence of TLp or TLb (0.1 to $5.0 \mu \mathrm{g})$ was compared. TLp treatment showed

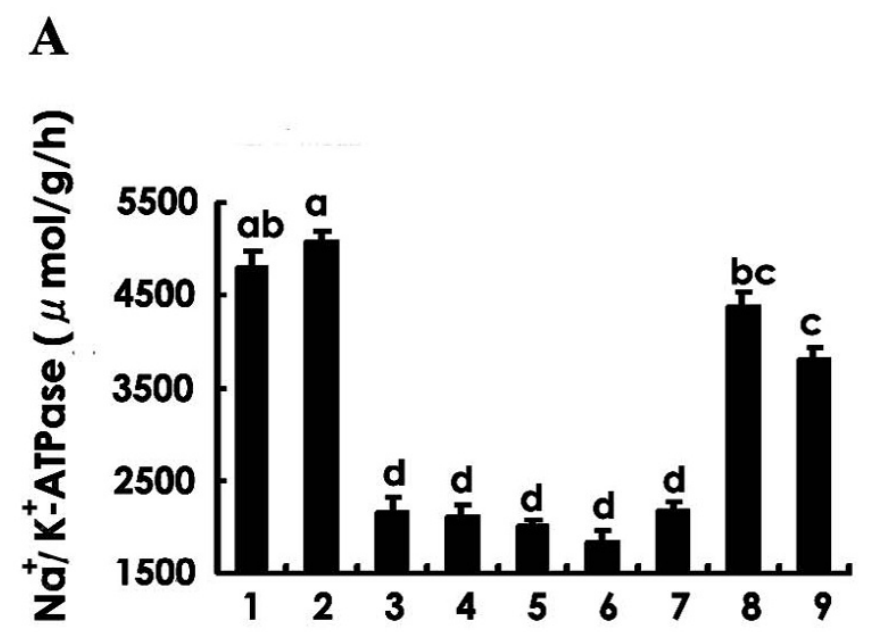

a statistically significant difference HTase activity as compared with treatment with TLb (Fig. 2B). TLp had a dosedependent stimulatory effect $(0.1 \mu \mathrm{g}$ to $1.0 \mu \mathrm{g})$ on HTase activity (columns 6 to 8 in Fig. 2B), and more than $5.0 \mu \mathrm{g}$ produced saturation of this effect. In contrast, TLb had no stimulating effect on HTase activity in the same dosage range (columns 2 to 4 , Fig. 2B).

On the other hand, PON1 activity in HDL was assayed using paraoxyethyl as a substrate, and there was no change upon the addition of TLp in the above dosage range (data not shown). This finding suggests that other PON isozymes may be responsible for TLp-induced HTase activation. The HTase/PON1 activity ratio calculated for each HDL sample showed a dose-dependent elevation by TLp (Fig. 3). One- and $5 \mu \mathrm{g}$ of TLp gave a statistically significant ratio increase as compared with lower amounts of TLp. This suggests that TLp has no effect on the activities of PON1, whereas it does have an effect on an isozyme such as PON3.

\section{Discussion}

In previous studies, a PR diet was reported to lower the elevation of blood glucose, type-1 plasminogen activator inhibitor, and lipid peroxide concentrations in STZinduced diabetic rats $[2,3]$. This finding suggested that $P R$ intake can ameliorate diabetic vascular complications, such as myocardial infarction, retinopathy, and nephropathy.

B

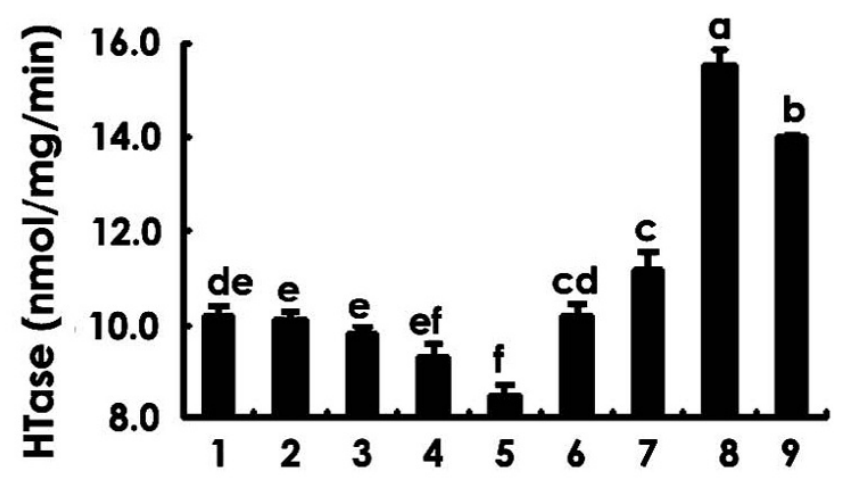

Figure 2

(A) Effects of modified LDL on $\mathrm{Na}^{+} / \mathrm{K}^{+}$-ATPase activity. Activity was assayed by incubation with the following: I, no additive; 2 , LDL; 3, HT-treated LDL ; 4, TLb (0.I $\mu \mathrm{g}) / \mathrm{HT}$-treated LDL; 5, TLb (I.0 $\mu \mathrm{g}) / \mathrm{HT}$-treated LDL; 6, TLb (I0 $\mu \mathrm{g}) / \mathrm{HT}$-treated LDL; 7 , TLp $(0.1 \mu \mathrm{g}) / \mathrm{HT}$-treated LDL; 8, TLp (I.0 $\mu \mathrm{g}) / \mathrm{HT}$-treated LDL ; 9 , TLp (10 $\mu \mathrm{g}) / \mathrm{HT}$-treated LDL. (B) Effects of total lipid extract on HTase activity. Activity was assayed by incubation with the following: I, no additive; 2 , TLb (0.I $\mu g) ; 3$, TLb (0.5 $\mu g) ; 4$, TLb $(1.0 \mu g) ; 5$, TLb $(5.0 \mu g) ; 6$, TLp $(0.1 \mu g) ; 7$, TLp $(0.5 \mu g) ; 8$, TLp $(I .0 \mu g) ; 9$, TLp $(5.0 \mu g)$. Values are means \pm SEM, $\mathrm{n}=6$ individual experiments. The data values were analyzed by one-way ANOVA followed by Tukey's multiple comparison test.

$a, b, c, d, d, f$ Values with different superscript letters differ significantly among the columns at $p<0.05$. 


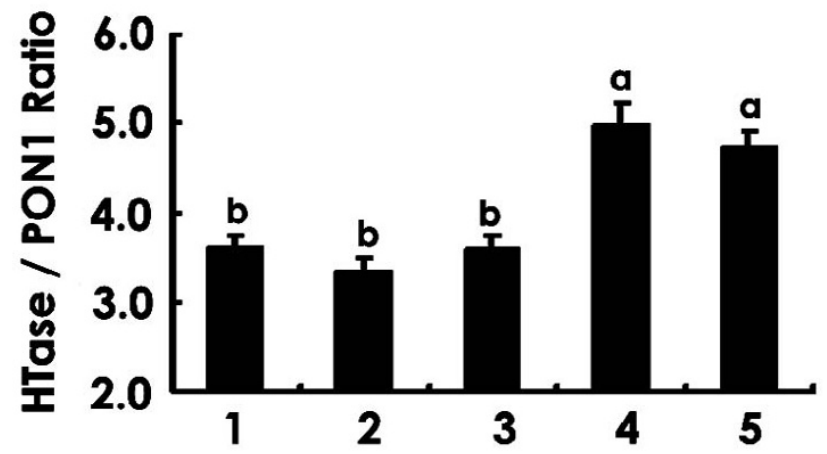

Figure 3

Effects of TLp on the ratio of HTase/PONI activities. HTase and PON I activities of HDL were assayed by incubation with the following: I, no additive; 2 , TLp $(0.1 \mu \mathrm{g})$; 3 , TLp $(0.5$ $\mu g)$; 4, TLp (I.0 $\mu \mathrm{g}) ; 5$, TLp $(5.0 \mu \mathrm{g})$. HTase activity corresponds to combined enzyme activities of PONI and PON3. Values are mean \pm SEM in individual experiments $(n=6)$. The data were analyzed by one-way ANOVA followed by Tukey's multiple comparison test. a,bValues with different superscript letters differ significantly among the columns at $p<0.05$.

We evaluated the effects of a PR diet on diabetic complications, especially peripheral neuropathy, in STZ-induced diabetic rats. We found that PR and BR diets lowered blood-glucose concentrations in diabetic rats, and that the PR diet had a statistically significant blood-glucose lowering effect $(p<0.01)$ as compared with the blood-glucose levels measured in rats on the BR diet (Table 2).

Although the non-diabetic and STZ-diabetic groups ate the same amount of diet, there was different gain in body weight. As the total energy available from protein, fat, and carbohydrate did not differ among the 3 diets (Table 1), the same intake of diet suggests that STZ-diabetic rats cannot sufficiently utilize the energy available from their diet. We speculate that the STZ-treatment injured the insulinsecreting beta cells, impairing glucose uptake into skeletal muscle and resulting in weight loss. Alternatively, the effect of STZ on hormonal functions of the adrenal glands might enhanced the basal metabolic rate. In the STZ-diabetic rats, the concentrations of noradrenaline are known to increase in a various tissues in these animals [31,32]. Thermogenesis is under control of the sympathetic nervous system, as noradrenaline has the ability to control biochemical pathways that increases mitochondrial oxidation rates and ATP synthesis, hence leading to an increase in heat production and not leading to the gain in body weight [33].

Our experiments showed that diabetic neuropathy was induced by STZ-treatment at 5 weeks, as evidenced by slowing of NCV and impairing of $\mathrm{Na}^{+} / \mathrm{K}^{+}-$ATPase activity
(Table 2), as well as to pathological changes consisting mainly of axonal degeneration in the sciatic nerves of the diabetic rats (data not shown). NCV values for all of the experimental rats, including diabetic and non-diabetic ones, correlated well with the sciatic-nerve membrane $\mathrm{Na}^{+} / \mathrm{K}^{+}$-ATPase activity values of individual diabetic and non-diabetic rats (Fig. 1). This result substantiated that measurement of $\mathrm{Na}^{+} / \mathrm{K}^{+}$-ATPase activity provides an additional measure to NCV for evaluating the severity of peripheral-nerve dysfunctions in animals. In our current study, the efficacy of the PR diet also was confirmed by morphometric analysis showing that axonopathy predominates over myelinopathy in STZ-diabetic rats. Abnormal fibers undergoing axonal degenerative changes and myelin breakdown are reported to appear in the sciatic [34] and phrenic [35] nerves of STZ-induced diabetic rats during prolonged hypoglycemia. Skewing of the $G$ ratio was corrected by the PR diet, giving an axonal diameter distribution similar to that for the non-diabetic animals.

Serum Hcy is a known risk factor for vascular disease and neurodegenerative disease [36] because an excess amount of Hcy generates HT with high toxicity [37]. Abnormal serum Hcy concentrations also have been observed in diabetic patients who develop peripheral vascular diseases. In our study, the total serum homocysteine of the DC group showed a decrease to $52.4 \%$ of the level for the $\mathrm{C}$ group (Table 2), a finding in agreement with those of previous studies [38-40]. The increase in serum creatinine in the DC group was probably due to complications caused by renal failure. The decrease in serum Hcy may have been produced by abnormal renal clearance. There is a possibility that in the beginning stages of STZ-induced diabetes, hepatic trans-sulfuration and re-methylation of the enzymes cystathionine $\beta$-synthase and cystathionine $\gamma$ lyase may increase in STZ-induced diabetic animals due to lack of insulin [40].

Although in our study the Hcy level decreased in the DC group, PR intake normalized the serum Hcy level as compared with that seen in WR- or BR-intake. Serum PON 1 activity decreases in STZ-induced diabetic rats [20] and in patients with vascular complications caused by type 2 diabetes mellitus [21,41-43]. PON has 3 isozymes, PON1, PON2, and PON3, which have distinct substrate specificities and tissue localization [17]. PON1 is associated with HDL and has been shown to reduce LDL susceptibility to lipid peroxidation. PON2 does not appear in serum. Whether the total HTase activity in human sera are affected by PON3 activity has not yet been determined [44]. PON1 is the only enzyme capable of hydrolyzing paraoxon, a metabolite of organophosphate parathion. PON1, PON2, and PON3, however, have the ability to hydrolyze a number of acyl-homocysteine thiolactone molecular species [17]. Serum Hcy produces HT that is 
toxic to the vascular system in diabetes. The activity of PON1 in serum and that of HTase in HDL decreased in STZ-induced diabetic rats, as reported previously [20,21]. Diabetic rats on a PR diet showed significant attenuation of PON1 and HTase activities as compared with those on a control diet. There is a significant correlation of both enzyme activities in diabetic rats on PR and BR diets. Interestingly, there also is a highly significant correlation between HTase and $\mathrm{Na}^{+} / \mathrm{K}^{+}$-ATPase activities of diabetic rats on a $\mathrm{PR}$, but not a $\mathrm{BR}$, diet. The significant association between these two enzymes may reflect the greater effectiveness of PR than of BR intake.

To investigate whether PR has an active factor(s) making it more effective than $\mathrm{BR}, \mathrm{Na}^{+} / \mathrm{K}^{+}$-ATPase activity was examined after incubation with HT-treated LDL and total lipids extracted from PR and BR brans (TLP and TLb, respectively). We found a significant decrease in $\mathrm{Na}^{+} / \mathrm{K}^{+}$ ATPase activity on incubation with HT-modified LDL as compared with incubation with intact LDL $(p<0.05)$ (Fig. $2 \mathrm{~A})$. Hcy has been reported to produce oxidative stress in rat hippocampal neurons by inhibiting $\mathrm{Na}^{+} / \mathrm{K}^{+}$-ATPase activity [14,15]. Vignini et al. [16] reported that HT-modified LDL attenuates $\mathrm{Na}^{+} / \mathrm{K}^{+}$-ATPase activity in cultured human aortic endothelial cells. We obtained a similar finding for the peripheral nervous system of diabetic rats. In our experiment, TLp ( 0.1 to $10 \mu \mathrm{g}) / \mathrm{HT}$-modified LDL gave a weak inhibition of $\mathrm{Na}^{+} / \mathrm{K}^{+}$-ATPase activity, whereas TLb/HT-modified LDL gave the same inhibition of $\mathrm{Na}^{+} /$ $\mathrm{K}^{+}$-ATPase activity as did HT-modified LDL. Neither TLp nor TLb alone produced any modification of $\mathrm{Na}^{+} / \mathrm{K}^{+}-$ ATPase activity (data not shown). This finding may suggest that TLp bears an inhibitory factor(s) that causes deprivation or attenuation of the effect of HT-treated LDL on $\mathrm{Na}^{+} / \mathrm{K}^{+}$-ATPase activity. This finding also may help to clarify the mechanism of the amelioration of diabetic neuropathy by PR intake. We demonstrated that TLp also directly enhanced the HTase activity of HDL (Fig. 2B). To estimate the enzyme activity ratio of PON3 to PON1+PON3, we assayed each enzyme activity by a substrate specificity of PON1 and HTase. The enzyme activity ratio of PON1 to HTase (Fig. 3) suggests that this enhancement may be due to the PON 3 present in HDL. PON3 is an HDL-related glycoprotein with multi-enzymatic properties and antioxidant activity, considered to aid in preventing LDL oxidation. PON3 bears many conserved phosphorylation and N-glycosylation consensus sites [45]. Modification at any of the sites required for activity in vivo, however, has yet to be shown. Possibly, PON3 protein has a hydrophobic binding site(s) against a lipid that regulates its activity. It is also possible that a certain unknown lipid component in PR may bind to PON3 and activate it. PR is expected to lower the postprandial blood-glucose increase, as is BR as compared with WR. Our research suggests that this efficacy may be based on higher concentrations of dietary fiber in BR and PR as compared with the fiber in WR. The PR diet includes almost the same amount of dietary fiber as BR. Our study showed, however, that the PR diet lowered rat blood-glucose levels significantly more than did BR (Table 2). Thus, compared with the BR diet, except for lowering of the blood-glucose level, which may be due to another PR intake mechanism, the PR diet mitigates diabetic neuropathy and is much more effective in easing peripheral nerve dysfunction.

\section{Conclusion}

We found that PR-diet intake in STZ-induced diabetic rats provided protection against deterioration of the peripheral nerve. An HTase-related mechanism contributed to the improvement of diabetic neuropathy. The total lipid extract of PR protected $\mathrm{Na}^{+} / \mathrm{K}^{+}$-ATPase from toxic HTmodified LDL and enhanced HTase activity of HDL. This protection could contribute to the efficacy of the PR diet in ameliorating the deleterious effects of diabetic neuropathy

\section{Abbreviations}

The abbreviations used are:

C: AIN93G diet control;

$\mathrm{G}$ ratio: Axonal diameter to total fiber diameter ratio;

Hcy: Homocysteine;

HTase: Homocysteine-thiolactonase;

HT: Homocysteine-thiolactone;

PBS: Phosphate-buffered saline;

PON: Paraoxonase;

STZ: Streptozotocin;

LDL: Low-density lipoprotein;

HDL: High-density lipoprotein;

ANOVA: Analysis of variance.

\section{Competing interests}

The author(s) declare that they have no competing interests.

\section{Authors' contributions}

SU participated in the concept and design of the study, data collection, tissue sampling, statistical analysis and drafting the manuscript. 
YI participated in animal experimentation.

KM participated in animal experimentation and carried out nutrients analysis

MK participated in the design of the animal study.

TA participated in lipid isolation and carried out lipid analysis.

MR participated in electrophysiology.

RKY participated in the design and interpretation of the study and drafting of the manuscript.

\section{Acknowledgements}

This work was supported by a project grant from FANCL.

\section{References}

I. FANCL: Pre-germinated brown rice. Patent 2005. No. 3738025, JP Nov 4

2. Hagiwara $H$, Seki T, Ariga $\mathrm{T}$ : The effect of pre-germinated brown rice intake on blood glucose and PAI-I levels in streptozotocin-induced diabetic rats. Biosci Biotechnol Biochem 2004, 68:444-447.

3. Ito Y, Mizukuchi A, Kise M, Aoto H, Yamamoto S, Yoshihara R, Yokoyama J: Postprandial blood glucose and insulin responses to pre-germinated brown rice in healthy subjects. J Med Invest 2005, 52:159-164.

4. Ito $Y$, Shen M, Kise M, Hayamizu K, Yoshino G, Yoshihara R, Yokoyama J: Effect of pre-germinated brown rice on postprandial blood glucose and insulin level in subjects with hyperglycemia. Jpn J Food Chem 2005, 12:80-84.

5. Seiki T, Nagase R, Torimitsu M, Yanagi M, Ito Y, Kise M, Mizukuchi A, Fujimura N, Hayamizu K, Ariga T: Insoluble fiber is a major constituent responsible for lowering the post-prandial blood glucose concentration in the pre-germinated brown rice. Biol Pharm Bull 2005, 28:1539-1541.

6. Saikusa T, Horino T, Mori Y: Distribution of free amino acids in the rice kernel and kernel fractions and the effect of water soaking on the distribution. J Agri Food Chem 1994, 42: I I 22-I I 25.

7. Oh SH: Stimulation of gamma-aminobutyric acid synthesis activity in brown rice by a chitosan/glutamic acid germination solution and calcium/calmodulin. J Biochem Mol Biol 2003, 36:319-325.

8. Sugimoto K, Murakawa $Y$, Sima AA : Diabetic neuropathy: a continuing enigma. Diabetes Metab Res Rev 2000, 16:408-433.

9. Dyck PJ, Zimmerman BR, Vilen TH, Minnerath SR, Karnes JL, Yao JK, Poduslo JF: Nerve glucose, fructose, sorbitol, myo-inositol, and fiber degeneration and regeneration in diabetic neuropathy. N Engl J Med 1988, 31 9:542-548.

10. Biessels G], Cristino NA, Rutten G], Hamers FP, Erkelens DW, Gispen WH: Neurophysiological changes in the central and peripheral nervous system of streptozotocin-diabetic rats. Brain 1999, I 22:757-768.

11. Leonelli E, Bianchi R, Cavaletti G, Caruso D, Crippa D, Garcia-Segura LM, Lauria G, Magnaghi V, Roglio I, Melcangi RC: Progesterone and its derivatives are neuroprotective agents in experimental diabetic neuropathy: A multimodal analysis. Neuroscience 2007, I 44: 1293-1304.

12. Vincent AM, Russell JW, Low P, Feldman EL: Oxidative stress in the pathogenesis of diabetic neuropathy. Endocr Rev 2004, 25:612-628.

13. Tesfaye S, Chaturvedi N, Eaton SE, Ward JD, Manes C, lonescu-Tirgoviste C, Witte DR, Fuller JH: EURODIAB Prospective Complications Study Group: Vascular risk factors and diabetic neuropathy. N Engl J Med 2005, 352:34I-350.

14. Streck EL, Zugno AI, Tagriari B, Franzon R, Wannmacher CM, Wajner $\mathrm{M}$, Wyse AT: Inhibition of rat brain $\mathrm{Na}^{+}, \mathrm{K}^{+}$-ATPase activity induced by homocysteine is probably mediated by oxidative stress. Neurochem Res 200I, 26:1 I95-1200.

15. Streck EL, Zugno Al, Tagliari B, Sarkis JJ, Wajner M, Wannmacher CM, Wyse AT: On the mechanism of the inhibition of $\mathrm{Na}^{+}, \mathrm{K}^{+}$. ATPase activity caused by homocysteine. Int J Dev Neuroscience 2002, 20:77-8I.

16. Vignini A, Nanette L, Bacchante T, Ferrety G, Curtail G, Mezzanine L: Modification induced by homocysteine and low-density lipoprotein on human aortic endothelial cells: An in vitro study. J Clin Endocrinol Metab 2004, 89:4558-456I.

17. Draganov DI, Teiber JF, Speelman A, Osawa Y, Sunahara R, La Du BN: Human paraoxonases (PONI, PON2, and PON3) are lactonases with overlapping and distinct substrate specificities. J Lipid Res 2005, 46: I239-1247.

18. Walker $\mathrm{CH}$, Mackness MI: "A" esterase and their role in regulating the toxicity of organophosphates. Arch Toxicol 1987, 60:30-33.

19. Mackness MI, Harty D, Bhatnagar D, Winocour PH, Arrol S, Ishola M, Durrington PN: Serum paraoxonase activity in familial hypercholesterolaemia and insulin-dependent diabetes mellitus. Atherosclerosis 1991, 86:193-199.

20. Patel BN, Mackness MI, Harty DW, Arrol S, Boot-Handford RP, Durrington PN: Serum esterase activities and hyperlipidaemia in the streptozotocin-diabetic rat. Biochim Biophys Acta 1990, 1035:113-116.

21. Abbott CA, Mackness MI, Kumar S, Boulton AJ, Durrington PN: Serum paraoxonase activity, concentration, and phenotype distribution in diabetes mellitus and its relationship to serum lipids and lipoproteins. Arterioscler Theromb Vascbiol 1995, 15(II): $1812-1818$.

22. Ferretti G, Bacchetti T, Marotti E, Curatola G: Effect of homocysteinylation on human high-density lipoproteins: Correlation with paraoxonase activity. Metabolism 2003, 52:|46-15I.

23. Kosaka T, Yamaguchi M, Motomura T, Mizuno K: Investigation of the relationship between atherosclerosis and paraoxonase or homocysteine thiolactonase activity in patients with type 2 diabetes mellitus using a commercially available assay. Clinica Chimica Acta 2005, 359: I56-162.

24. Andersen H, Nielsen JF, Nielsen VK: Inability of insulin to maintain normal nerve function during high-frequency stimulation in diabetic rat-tail nerves. Muscle \& Nerve 1994, 17:80-84.

25. Usuki S, Thompson SA, Rivner MH, Taguchi K, Shibata K, Ariga T, Yu RK: Molecular mimicry: Sensitization of Lewis rats with Campylobacter jejuni lipopolysaccharides induces formation of antibody toward GD3 ganglioside. J Neurosci Res 2006, 83:274-284.

26. Folch J, Lees M, Sloane Stanley GH: A simple method for the isolation and purification of total lipids from animal tissues. J Biol Chem 1957, 226:497-509.

27. Chung BH, Wilkinson T, Geer JC, Segrest JP: Preparative and quantitative isolation of plasma lipoproteins: rapid, single discontinuous density gradient ultracentrifugation in a vertical rotor. J Lipid Res 1980, 21:284-291.

28. Silva IV, Caruso-Neves C, Azeredo IM, Carvalho TLG, Lara LS, de Mello MC, Lopes AG: Urea inhibition of renal $\left(\mathrm{Na}^{+}+\right.$ $\left.\mathrm{K}^{+}\right)$ATPase activity is reversed by cAMP. Arch Biochem Biophys 2002, 406: $183-189$.

29. Adeoye BA, Oyedapo OO: Toxicity of erythrophleum guineense stem-bark: role of alkaloidal fraction. Afr J Trad CAM 2004, I:45-54.

30. Rossini AA, Like AA, Dulin WE, Cahill GF Jr: Pancreatic beta cell toxicity by streptozotocin anomers. Diabetes 1977, 26: II $20-1124$.

31. Fushimi H, Inoue T, Namikawa H, Kishino B, Nishikawa M, Tochino $Y$, Funakawa S: Increased norepinephrine content in diabetic rat heart. J Biochem 1982, 91:1805-1807.

32. Lucas PD, Qirbi A: Tissue noradrenaline and the polyol pathway in experimentally diabetic rats. $\mathrm{Br} J$ Pharmacol 1989, 97:347-352.

33. Dulloo AG: Biomedicine. A sympathetic defense against obesity. Science 2002, 297:780-781.

34. Sugimoto $K$, Yagihashi S: Peripheral nerve pathology in rats with streptozotocin-induced insulinoma. Acta Neuropathol 1996, 91:616-623. 
35. Rodrigues Filho OA, Fazan VP: Streptozotocin induced diabetes as a model of phrenic nerve neuropathy in rats. J Neurosci Meth 2006, I5I:131-138.

36. Abdella NA, Mojiminiyi OA, Akanji AO, Moussa MA: Associations of plasma homocysteine concentration in subjects with type 2 diabetes mellitus. Acta Diabetol 2002, 39:183-190.

37. Jakubowski $\mathrm{H}$ : Pathophysiological consequences of homocysteine excess. J Nutr 2006, I36: I74IS-1749S.

38. Unlucerci Y, Bekpinar S, Gurdol F, Seferoglu G: A study of the relationship between homocysteine and diabetic nephropathy in rats. Pharmacol Res 2002, 45:249-252.

39. Gursu MF, Baydas G, Cikim G, Canatan H: Insulin increases homocysteine levels in a dose-dependent manner in diabetic rats. Arch Med Res 2002, 33:305-307.

40. Jacobs RL, House JD, Brosnan ME, Brosnan JT: Effect of streptozotocin-induced diabetes and of insulin treatment on homocysteine metabolism in the rat. Diabetes 1998, 47:1967-1970.

4I. Juretic D, Motejlkova A, Kunovic B, Rekic B, Flegar-Mestric Z, Vujic L, Mesic R, Lukac-Bajalo J, Simeon-Rudolf V: Paraoxonasel arylesterase in serum of patients with type II diabetes mellitus. Acta Pharm 2006, 56:59-68.

42. Lakshman MR, Gottipati CS, Narasimhan SJ, Munoz J, Marmillot P, Nylen ES: Inverse correlation of serum paraoxonase and homocysteine thiolactonase activities and antioxidant capacity of high-density lipoprotein with the severity of cardiovascular disease in persons with type 2 diabetes mellitus. Metabolism 2006, 55: I 201 I-1206.

43. Moldoveanu E, Tanaseanu C, Tanaseanu S, Kosaka T, Manea G, Marta DS, Popescu LM: Plasma markers of endothelial dysfunction in type 2 diabetics. Eur J Intern Med 2006, 17:38-42.

44. Reddy ST, Wadleigh DJ, Grijalva V, Ng C, Hama S, Gangopadhyay A, Shih DM, Lusis AJ, Navab M, Fogelman AM: Human paraoxonase3 is an HDL-associated enzyme with biological activity similar to paraoxonase-I protein but is not regulated by oxidized lipids. Arterioscler Thromb Vasc Biol 2001, 21:542-547.

45. Rodrigo L, Gil F, Hernandez AF, Lopez O, Pla A: Identification of paraoxonase 3 in rat liver microsomes: purification and biological properties. Biochem J 2003, 376:26I-268.

Publish with Bio Med Central and every scientist can read your work free of charge

"BioMed Central will be the most significant development for disseminating the results of biomedical research in our lifetime. "

Sir Paul Nurse, Cancer Research UK

Your research papers will be:

- available free of charge to the entire biomedical community

- peer reviewed and published immediately upon acceptance

- cited in PubMed and archived on PubMed Central

- yours - you keep the copyright 